\title{
Examining the effectiveness of measuring team brand association networks with textual analysis software
}

\section{Patrick Walsh*}

Department of Sport Management, Syracuse University, 301 MacNaughton Hall, Syracuse, NY 13244, USA

Email: ptwalsh@syr.edu

*Corresponding author

\section{Galen Clavio}

\author{
National Sports Journalism Center, \\ The Media School, \\ Indiana University, \\ 601 E. Kirkwood Ave., \\ Bloomington, IN 47405, USA \\ Email: gclavio2@indiana.edu
}

\begin{abstract}
As brand associations are a key component of team brand equity, and ultimately influence consumer behaviour, it is important to have accurate measures of these associations. Previous research has developed scales to measure team brand associations, yet it has been suggested that pre-existing scales may not capture salient features of brands and any unique brand associations not captured by scaled measures. In addition, scales will not uncover the brand association networks and how team brand associations are interconnected. However, with advances in technology there is potential to develop methods which accomplish these goals. This study utilises a freethought listing technique to capture team brand associations which were then analysed by the Leximancer textual analysis software. The results suggest that this method provides an avenue to more accurately uncover the most salient team brand associations and to visualise team brand association networks.
\end{abstract}

Keywords: team brand associations; brand equity; brand association networks; Leximancer.

Reference to this paper should be made as follows: Walsh, P. and Clavio, G. (2019) 'Examining the effectiveness of measuring team brand association networks with textual analysis software', Int. J. Sport Management and Marketing, Vol. 19, Nos. 5/6, pp.293-312.

Biographical notes: Patrick Walsh is an Associate Professor in the David B. Falk College of Sport and Human Dynamics at Syracuse University. His research focuses on the brand management practices of sport organisations and how they can best harness the power of their brands to further business objectives. 
Galen Clavio is the head of the Sports Media program in The Media School at Indiana University. He also serves as the director of the National Sports Journalism Center. He is the author of over 40 peer-reviewed articles and is a frequent contributor to national media on subjects relating to sports media. His research focuses on the utilisation of new and electronic media in sports, and in particular how it affects the interactions between sports teams, fans, and other stakeholders. He is the co-author of an upcoming book on multimedia sports journalism.

\section{Introduction}

One of the key factors influencing a sport organisation's marketing and business success is the ability to create brand equity, which is the set of assets or liabilities associated with a brand name that either add to or subtract from the brand's overall value (Aaker, 1991). Brand equity has commonly been thought to be comprised of a consumer's awareness of the brand, their loyalty towards the brand, perceived quality of the brand, and the brand associations or image they hold for the brand (Aaker, 1996; Keller, 1993). While research on brand equity has been studied in some depth outside of sport by notable brand management theorists (e.g., Aaker, 1991, 1996; Keller, 1993), brand equity research in sport is still relatively in its early stages (Ross et al., 2008). In fact, it has been suggested that while some scholars are beginning to focus more attention on conceptualising and measuring brand equity in sport, much more work is needed in this area. In particular, understanding the brand associations which contribute to an organisation's brand equity is key to maintaining a successful organisation (Gladden et al., 2001).

In sport there are three notable brand equity frameworks (Gladden et al., 1998; Gladden and Milne, 1999; Ross, 2006). While each of these frameworks do have minor differences, they all contend that there are a variety of factors which will impact team brand equity. For example, the team's head coach, players, stadium, and a large variety of other factors will influence the various components of a team's brand equity. In addition, each brand equity framework includes both brand awareness and brand associations as components of team brand equity. Brand awareness represents an individual's ability to recall or recognise a brand (Aaker, 1996) while brand associations are the thoughts a consumer holds in their memory for a particular product or service which ultimately form the brand's image (Aaker, 1996; Keller, 1993).

In sport, it has been suggested that brand associations are a key component in the development of loyalty towards a team and the ability for the team to generate revenue from consumers and potential business partners (Ross, 2006). Further, it is suggested that team brand associations are the most important factor to understand when examining team brand equity as brand associations are most commonly used by consumers when making purchase decisions (Aaker, 1996; Ross, 2006). As such, it is important for sport organisations to have accurate measures of their brand associations. While previous scaled measures of team brand associations have contributed to our knowledge in this area (e.g., Gladden and Funk, 2002; Ross et al., 2006), it has been suggested that preexisting scales cannot capture the most salient and unique features of brands (Heere, 2010; Walsh et al., 2013), or uncover the brand association networks which describe the relative strength of the associations and how the collection of brand associations are 
interconnected (John et al., 2006). Therefore, it is important for research to continue to develop new and unique methods which measure and analyse team brand associations. This study will extend our knowledge of brand association measurement by examining the utility of using a textual analysis software, Leximancer, to measure team brand associations. Specifically, this study will analyse what brand associations are uncovered using the textual analysis software, determine the relative strength and interconnectedness of the associations, and make comparisons between the associations uncovered using Leximancer versus a more traditional scaled brand association measurement technique.

\section{Literature review}

\subsection{Measuring brand associations}

Due to the importance of having sound measurements of team brand associations in sport a variety of different studies have attempted to determine the most appropriate method of measurement. For example, Gladden and Funk's (2002) team association model (TAM) was the first sport specific scale designed to measure team brand associations. This model identified brand associations which could be classified as attribute (i.e., success, head coach, star player, management, stadium, logo design, product delivery, and tradition), benefit (i.e., team identification, nostalgia, pride in place, peer group acceptance, and escape), and attitude associations (i.e., the team's personal relevance, fan's knowledge of the team, and affect). To further the study of team brand associations in sport, Ross et al. (2006) noted some issues with the TAM and created the team brand association scale (TBAS). The final TBAS is a 41-item scale which measures 11 team brand association dimensions including brand mark, rivalry, concessions, social interaction, team history, commitment, organisational attributes, non-player personnel, stadium community, team success, and team play.

While the TAM and TBAS have added considerably to the study of brand associations in sport they may not represent the most complete way to measure team brand associations due to their limitations in examining any further unique brand associations which are not captured by the scales. In particular, both the TAM and TBAS ask respondents to rate their level of agreement with the preexisting scaled brand association items. While this measures if respondents agree with the statements, it does not provide information on what team brand associations are most prominent for the consumer. Previous research supports this thinking that preexisting scales may not capture the uniqueness of certain brands (Heere, 2010; Walsh et al., 2013). If this is true, scaled measurements of team brand associations may not provide a complete understanding of a team's brand associations. This can be extremely detrimental to an organisation as any marketing strategies based solely on preexisting scaled results may cause the brand to be positioned with biased misinformation (Ross et al., 2006; Supphellen, 2000). In addition, opportunities to enhance the brand through brand extensions and co-branding opportunities may be missed as the organisation may not have a true understanding of which of their associations are most relevant to other categories and brands (Supphellen, 2000).

In addition, previous research has suggested that while scales may be helpful in providing an initial understanding of brands, they cannot detect brand association 
networks (John et al., 2006). In other words, team brand association scales will not tell us which associations are directly connected to the brand and how all of the different types of brand associations may be interconnected. Because of this it is important to identify brand associations based on responses to open-ended questions as opposed to preexisting scales as open-ended questions will measure which brand associations are most accessible in memory, and ultimately most important, for the consumer (John et al., 2006).

This concept of brand association networks is based in research on memory and the associative network memory model (Wickelgren, 1981). This model describes human memory as consisting of a particular set of items of elements, known as nodes, which are representative of certain ideas in our memory. Similar to the definition of brand associations, these nodes can ultimately be 'anything which represents an idea' in memory [Wickelgren, (1981), p.24]. An individual will have multiple nodes for an item which are stored in their memory and may be connected together, ultimately becoming a stronger representation in memory of the idea with multiple interactions (Wickelgren, 1981). Retrieval of these nodes, or in the case of this study retrieval of team brand associations, will occur when some stimulus (e.g., exposure to a team logo, advertisement, game, etc.) activates the nodes in memory. The stronger the connections between each of the nodes the more likely they will be retrieved. When discussing brand associations, the retrieval of these nodes can be described as either first-order associations or second-order associations. A first order association is an association which is directly connected to the brand, while a second-order association is one which is connected to the brand through the first order association (Schnittka et al., 2012).

Previous research has attempted to measure these brand association networks by creating brand concept maps which identify important brand associations and visually depict how the brand associations are interconnected (e.g., John et al., 2006; Schnittka et al., 2012). This visual depiction generally includes the brand name in the centre of the map with brand associations connected to the brand in the centre with various lines representing the strength of the associations.

While this method of brand association measurement has been slow to develop (John et al., 2006), there are multiple ways in which concept maps have been produced. However, there is generally a multi-stage approach. For example, John et al. (2006) used an approach where brand associations were elicited using an open-ended question, participants were then instructed on how to produce a brand concept map using either their associations or 25 pre-selected associations, the participants then drew their map by hand and then quantitatively measured their feelings towards the brand. The researchers would then use another multi-step approach to code the maps, determine which associations were most salient, and where the associations would be placed on a consensus map developed by the researchers. Further research has used a similar approach of brand association measurement by including measurement factors such as the favourability of the brand associations (Schnittka et al., 2012). While the development of brand concept maps in this manner is a robust method, this is a long process with increased potential for error. In addition, researcher developed consensus maps introduce the potential for researcher bias when determining the first and second order associations. However, with the introduction of new technologies and software which can analyse open-ended brand association responses there is the potential to develop visual brand concept maps in a more practical manner which removes bias by 
eliminating the need for researchers to develop a consensus brand concept map. One such program which is worth examining is Leximancer.

\subsection{Measuring text using Leximancer}

Leximancer is textual analysis software which performs content analysis of large groups of text such as open-ended survey responses used in this study. Once the data is uploaded to the software, the Leximancer program will conduct both a thematic and semantic analysis of the text to determine the key themes and how the themes relate to each other (Campbell et al., 2011). These themes are then displayed visually in a concept map which also provides a visual representation of their relative importance and interconnectedness. Given this functionality, it is suggested that the Leximancer software performs similar analysis to previous research which has attempted to manually develop brand concept maps (e.g., John et al., 2006; Schnittka et al., 2012). Specifically, the software identifies key themes (i.e., brand associations), their relative importance and frequency in the text (i.e., saliency of the brand associations), and how these themes are connected (i.e., brand association networks) without the need for an arduous multi-step procedure typically used to create brand concept maps.

While Leximancer has been used in a variety of settings, in sport it has been primarily used to analyse the text in social media posts. For example, it has successfully been used to analyse the content of sponsor tweets during the 2014 Sochi Winter Olympic Games (Abeza et al., 2014), the use of a sponsored Twitter hashtag during the same Olympic games (Pegoraro et al., 2014), the responses to an athlete's public statement following a crisis (Frederick et al., 2016), and how a country's national sport governing bodies were utilising Twitter (Naraine and Parent, 2016).

Given the importance of having sound measurements of team brand associations it is critical that research continues to examine new ways to measure brand associations. As previously mentioned, some researchers have begun to use methods to examine brand associations by creating brand concept maps (e.g., John et al., 2006; Schnittka et al., 2012). However, the process to do so is time consuming and can lead to error. However, given Leximancer's ability to analyse large groups of text, and to provide a visual representation of the major themes in the text, the software has the potential to be able to analyse team brand associations and brand association networks in a more streamlined and practical manner. This study will be the first to attempt to examine the potential effectiveness of using Leximancer to identify team brand associations and team brand association networks. By doing so this study will extend our knowledge of team brand association measurement while addressing the following research questions:

RQ1 What team brand association themes are uncovered utilising the textual analysis software Leximancer?

RQ2 Are there any differences in the salient brand associations uncovered by Leximancer when compared to the associations examined utilising the existing team brand association scale (TBAS)?

RQ3 What impact does team identification have on the stated brand associations identified by Leximancer when compared to the TBAS? 


\section{Methodology}

\subsection{Sample}

In order to address the study's research questions a self-administered web-based survey was distributed to a nationwide sample of sport fans in the USA $(n=385)$. This sample was obtained using Qualtrics Panel Management - a service provided by the Qualtrics Survey Platform which allows researchers to access and target select individuals for survey participation.

Prior to being allowed to participate in the survey, the participants who Qualtrics recruited were required to answer three screening questions. First, they were asked a simple yes or no question if they are 18 years of age or older. Only those who indicated they were at least 18 years of age were permitted to continue with the survey. In addition, this study targeted participants who have some interest in professional sports. Similar to a method utilised by Walsh and Williams (2017), participants were asked to rate their level of interest in professional sports on a scale of 1 to 7 with 1 being 'not interested at all' and 7 being 'very interested'. Any participant who scored three or above on this question was identified as someone with at least some interest in sport (Walsh and Williams, 2017). As such, they were allowed to continue with the survey, while those scoring two or less were automatically timed out of the survey. Finally, the participants were asked if they have a favourite professional sports team. If they indicated in the affirmative it was determined that they were a qualified participant for the study.

\subsection{Survey instrument}

Following the screening questions, qualified participants were first asked to list the name of their favourite professional sports team. This question acted as a stimulus to get the participants thinking about their favourite team, and thus enhances the likelihood of capturing a participant's personal thoughts and feelings that they hold for the team's brand during the remainder of the survey questions (Kowalczyk and Royne, 2013). In order to elicit the brand associations, and to address RQ1, a qualitative free-thought listing technique was utilised. Specifically, participants were asked to write the first thoughts that come to mind when they think about their favourite professional sports team. Similar to previous research which has examined brand associations utilising free-thought listings (e.g., Chen, 2001; Grace and O'Cass, 2002; Ross et al., 2006; Walsh et al., 2015; Williams et al., 2015) this technique captures the specific team brand associations an individual holds for their favourite sports team. Specifically, using an open-ended free-thought listing technique allows participants to identify which brand associations are most meaningful to the participant and to describe this in their own words (John et al., 2006). In addition, free-thought listing is one of the most common open-response methods to obtain cognitive responses as it captures the immediate response an individual has for a stimulus (i.e., their favourite team) while at the same time decreasing the potential for a participants to forget the actual stimulus (Cacioppo and Petty, 1981).

Following the free-thought listing question, participants responded to the TBAS in order to provide a quantitative measure of team brand associations and to be able to address RQ2. The TBAS was chosen as the most appropriate scaled measure of team brand associations as it is the scale which has been most commonly utilised in a variety 
of research settings (e.g., Biscaia et al., 2013; Ross and James, 2007; Ross et al., 2007; Walsh and Ross, 2010). Specifically, participants were asked to rate their level of agreement with each of the items using a 7-point Likert scale anchored by strongly disagree (1) and strongly agree (7).

Finally, in order to address RQ3, the participants' level of identification with their favourite team was used as a measure of their psychological commitment to the team. This is being examined in this study as an individual's commitment to the team has been shown to influence team brand association ratings (e.g., Ross and James, 2007; Walsh and Ross, 2010). In addition, in previous literature which has developed brand concept maps it was determined that consumers who are highly involved with a brand have different associations from consumers with low levels of involvement (Schnittka et al., 2012). Therefore, in order to provide a detailed analysis of team brand associations using Leximancer, and to further our knowledge of team brand associations, it was deemed beneficial to compare the brand association concept maps among those at varying levels of identification - which in this study is defined as a measure of an individual's commitment to a team and how connected they feel with a particular team (Ross et al., 2008). To measure one's level of identification with the team participants rated their level of agreement with the following four statements: The <insert favourite team $>$ is my team, I consider myself a loyal fan of <insert favourite team>, supporting the <insert favourite team $>$ is very important to me, and I want others to know that I am a fan of <insert favourite team $>$ (Ross et al., 2008).

Table 1 Team brand association scale (TBAS) constructs and items

\begin{tabular}{lll}
\hline Construct & 1 & The team has distinctive colours \\
\hline Brand mark & 2 & The symbol of the team is unique \\
3 & The team's logo is different from others \\
& 1 & The team has a tough conference \\
& 2 & The team often beats their biggest opponents \\
Rivalry & 3 & The team does well against their major rivals \\
& 1 & The concessions at the arena or stadium are excellent \\
& 2 & There are specific foods at the arena or stadium I like to eat \\
Concessions & 3 & I enjoy eating at the arena or stadium \\
& 1 & The team offers me a place to spend time with friends \\
& 2 & Being a fan of the team is a good way to meet other people \\
& 3 & I am able to see friends because of the team \\
& 4 & The team provides a good place to see friends \\
& 1 & The team has many loyal fans supporting them \\
2 & Many fans regularly follow the team \\
3 & The loyalty of the fans is very noticeable \\
4 & Fans have followed the team for a long time \\
\hline \multirow{3}{*}{ Commitment } &
\end{tabular}

Source: Adapted from Ross et al. (2008) 
Table 1 Team brand association scale (TBAS) constructs and items (continued)

\begin{tabular}{|c|c|c|}
\hline Construct & & Items \\
\hline \multirow[t]{3}{*}{ Team history } & 1 & The team has a history of winning \\
\hline & 2 & The team has a rich history \\
\hline & 3 & The team has been successful in the past \\
\hline \multirow[t]{3}{*}{ Organisational attributes } & 1 & The team is committed to its fans \\
\hline & 2 & The team is very loyal to its fans \\
\hline & 3 & The devotion to the fans by the team is obvious \\
\hline \multirow[t]{4}{*}{ Team success } & 1 & The team is not very successful (reverse scored) \\
\hline & 2 & The team is a great team \\
\hline & 3 & The team is not very high quality (reverse scored) \\
\hline & 4 & The team has high quality players \\
\hline \multirow[t]{3}{*}{ Team play } & 1 & The team has a clear personality (e.g., dedicated, hard working) \\
\hline & 2 & The team has distinct qualities (e.g., intensity, commitment) \\
\hline & 3 & The team has unique characteristics (e.g., trusted, responsive) \\
\hline \multirow[t]{3}{*}{ Non-player personnel } & 1 & The team's personnel do a fantastic job \\
\hline & 2 & The team has excellent coaches \\
\hline & 3 & The management of the team is outstanding \\
\hline \multirow[t]{3}{*}{ Stadium } & 1 & The arena or stadium has unique characteristics \\
\hline & 2 & The design of the stadium or arena is excellent \\
\hline & 3 & $\begin{array}{l}\text { The stadium or arena enhances the enjoyment of going to see } \\
\text { the game }\end{array}$ \\
\hline
\end{tabular}

Source: Adapted from Ross et al. (2008)

\subsection{Data analysis}

In order to address RQ1 the free-thought listing data from each of the participants was recorded and entered into Leximancer. As previously discussed, computer-aided textual analysis has been used successfully in a variety of prior literature, particularly in the area of sport and social media and the language used by audiences (e.g., Abeza et al., 2014; Pegoraro et al., 2014). Using this type of analysis to examine team brand associations is beneficial as the software will be able to identify related concepts within the text provided by the participants, the relationships which may exist between the brand associations, and it will provide a visual brand concept map with shared themes amongst the text (Sotiriadou et al., 2014). This analysis provided by Leximancer thus eliminates the potential for human error with traditional content analysis and increases coding reliability and validity (Abeza et al., 2014).

In order to examine RQ2 the means of the 11 TBAS dimensions were calculated to first understand which of the 11 dimensions the participants felt were representative of their favourite professional sport teams. Those means were then compared to the salient brand associations uncovered in the Leximancer analysis to determine if there are any similarities or differences in the types of associations mentioned in the free-thought listing versus the associations rated using the pre-existing TBAS. 
To address RQ3 respondents were segmented into high, moderate, and low levels of identification based on their mean scores for each scale (Ross et al., 2008). Similar to previous research (e.g., Walsh et al., 2012) participants below the mid-point with a mean score between 1 and 3.99 were deemed to have low levels of identification, those between 4 and 5.99 were classified as having moderate levels of identification, and participants with a mean score between 6 and 7 were determined to have high levels of identification. After segmenting the respondents into each of the groups, the brand associations from the free-thought listing question for each identification group were analysed. The corresponding themes, frequencies, and concept maps were then examined to determine if there were any differences in the team brand associations mentioned based on levels of identification. Utilising multivariate analysis of variance (MANOVA) the 11 TBAS dimensions were also examined for mean differences between those at low, moderate, and high levels of identification. The difference between the MANOVA results and the results from Leximancer was examined to further analyse the potential utility of using textual analysis software to analyse team brand associations versus using preexisting scales.

\section{Results}

A total of 420 survey responses were collected. However, after cleaning the data by eliminating any participants with straight line responses and removing any non-response to the free thought listing question, a final sample of 385 participants was utilised for this study. The sample self-identified as being predominately White/Caucasian $(77.9 \%)$ with an average age of nearly 50 years old $(M=49.56)$. Further, there was a wide range of ages with $24.4 \%$ of the sample between the ages of 18 and $30,35.1 \%$ between the ages of 31 and $50,40.5 \%$ over the age of 50 , and $71.7 \%$ of the participants had at least some college education or had earned a college degree. In addition, the sample was generally highly identified with their favourite team $(M=6.14)$.

In order to address RQ1, the results from the Leximancer analysis, and the resulting concept map were examined (see Figure 1). In the results that follow, n represents the number of times the terms were identified in the data. As noted in Figure 1, at the centre of the brand concept map is the theme of team and a variety of additional brand association themes then branch off of this main concept and overlap with the team theme. This overlapping illustrates that the themes are semantically linked together, thus highlighting the brand association networks and the interconnectedness of the brand associations.

The primary brand association themes that emerged were: team $(n=210)$, fan $(n=$ $86)$, play $(n=71)$, exciting $(n=56)$, favourite $(n=44)$, and football $(n=7)$. The team theme included a variety of descriptors including some key items which could be deemed as specific brand associations such as mentions of specific players $(n=54)$, moments in the team's history $(n=14)$, their connection to the team and players (represented by love, $n=30$ ), and the team's success (represented by won, $n=13$ and best, $n=24$ ). Further analysis of the connected brand association themes provides more details into these salient brand associations and the brand's associative network. 
Figure 1 Leximancer brand concept map for full sample (see online version for colours)

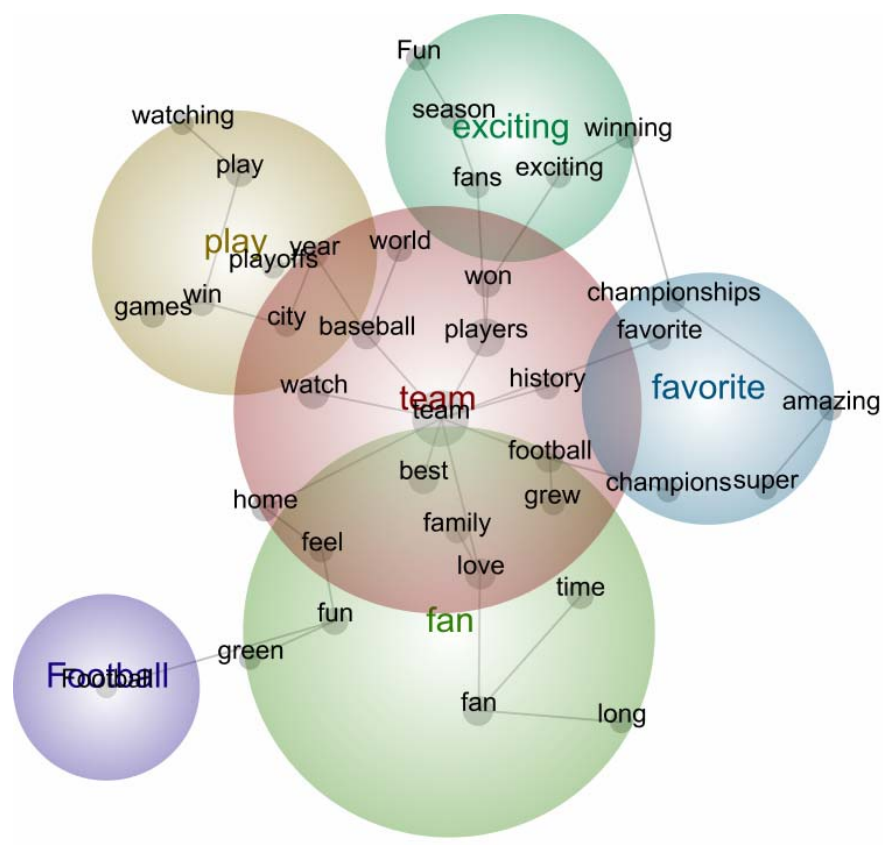

The fan theme represented the common representation of participants expressing their fandom and how long they have been a fan. For instance, comments such as "I have been a fan for a very long time" and "I have been a fan for 35 years and they are a part of my childhood and adulthood" highlight the fans associating their time spent as a fan as a specific brand association. In addition, many comments such as "I think of my dad who was a Dodger fan when they were in Brooklyn" highlight the association of family and interacting with family as part of one's brand associations for their favourite team.

The play theme primarily revolved around the concept of team success as a brand association with comments such as "After many years of playing losing baseball, they have finally begun to win games that put them into the playoffs", "They don't play to wow the fans, they play to win it all", and "The team finally captured its first NBA title after 52 year title drought in Cleveland". The exciting theme also focused on characteristics of the team, but as opposed to team success this theme uncovered brand associations connected to the team's style of play. Comments such as "They are exciting to watch and extremely talented", "They're tough but considered a bit of an underdog", and "Hard working and one of the top teams in their sport" highlight this association. Finally, the football theme was a secondary theme as noted by its placement on the map and lack of overlap with the other themes. However, this theme occurred as some participants would simply mention the sport of their favourite team, in this case football.

Ultimately the analysis of RQ1 identified the salient team brand associations to include the team's players, various aspects of the team's history including the success of the team, the team's style of play or human personality descriptors of the team (e.g., fun, young, exciting, etc.), and bonding or social interaction with family members. In addition, aspects of psychological connection to the team (i.e., identification and 
internalisation) were certainly a common theme in the analysis with participants highlighting how long they have been a fan of the team.

Prior to examining RQ2 Cronbach's alpha for each of the TBAS constructs were calculated to assess the reliability of the scale in this setting. Upon initial examination all but four of the constructs met the minimum cutoff level of .70 as suggested by Nunnally and Bernstein (1994); rivalry (.466), concessions (.541), team history (.435), and organisational attributes (.451). After further analysis it was determined that one item in each of the four constructs was influencing the reliability. In particular, it was found that items which were reverse scored for the rivalry, concessions, and team history constructs (one within each construct) should be removed to establish reliability, and perhaps the wording of those items caused confusion for the participants. As such, those items, along with one item for organisational attributes, were removed. Upon doing so all TBAS constructs were deemed to be reliable with Cronbach alpha ranging of a low of .744 for team success to a high of .871 for organisational attributes. A confirmatory factor analysis was then conducted in AMOS to determine the validity of the TBAS in this setting. While examining multiple fit indices the scale was found to be moderately valid. When reviewing AVE only the team success construct failed to meet Hair et al.'s (2010) suggested level of .50. However, the remaining 10 constructs were all above this minimum level and all 11 constructs combined had a mean AVE of .618. In addition, RMSEA (.069) and CFI (.896) met recommended thresholds while TLI (.880) fell just short of the recommended .90 cutoff (Hu and Bentler, 1999). After taking all items into consideration the TBAS was deemed to be valid for further analysis in this study.

Table 2 TBAS construct means

\begin{tabular}{lcccc}
\hline TBAS construct & Mean & Low ID & Moderate ID & High ID \\
\hline Commitment & 6.30 & 5.67 & 5.72 & $6.58^{* *}$ \\
Organizational attributes & 6.16 & 5.08 & 5.45 & $6.61^{* *}$ \\
Brand mark & 6.05 & 4.75 & 5.47 & $6.34^{* *}$ \\
Team history & 6.00 & 5.96 & 5.45 & $6.26^{* * *}$ \\
Team play & 5.97 & 4.13 & $5.28^{*}$ & $6.34^{* *}$ \\
Stadium & 5.84 & 4.96 & 5.13 & $6.19^{* *}$ \\
Non-player personnel & 5.72 & 4.20 & $5.07^{*}$ & $6.06^{* *}$ \\
Rivalry & 5.69 & 4.29 & 5.10 & $5.99^{* *}$ \\
Team success & 5.68 & 4.40 & 5.18 & $5.95^{* *}$ \\
Social interaction & 5.26 & 3.09 & $4.38^{*}$ & $5.73^{* *}$ \\
Concessions & 5.12 & 2.83 & $4.46^{*}$ & $5.49^{* *}$ \\
\hline
\end{tabular}

Notes: * Significant difference between moderate and low ID at $p<.01$.

**Significant difference between high and both moderate and low ID at $p<.01$.

*** Significant difference between just high and moderate ID at $p<.01$

After establishing reliability and validity, and in order to address RQ2 and determine if any differences exist between the results in the brand associations uncovered using Leximancer and the brand associations identified using the TBAS, the means of the 11 TBAS constructs were computed. As noted in Table 2, the highest rated brand associations using the preexisting scale were commitment $(M=6.30)$, organisational 
attributes $(M=6.16)$, and brand mark $(M=6.05)$. Following the top three were team history $(M=6.00)$, team play characteristics $(M=5.97)$, stadium $(M=5.84)$, non-player personnel $(M=5.72)$, rivalry $(M=5.69)$, team success $(M=5.68)$, social interaction $(M=5.26)$, and concessions $(M=5.07)$.

In comparing the Leximancer output to the results of the TBAS there were some similarities and differences in the team brand associations. In terms of similar results, the top-rated association construct of commitment, which measures the loyalty of the fans and the length of time fans have supported the team in the TBAS, was a prevalent brand association theme uncovered by Leximancer. In addition, the team history, team success, and team play characteristics TBAS constructs were all represented by the first order brand association themes uncovered by Leximancer.

However, the Leximancer results did not uncover any common themes related to the brand mark, rivalry, concessions, non-player personnel, and stadium association constructs, all of which had moderate to high means when examined using the TBAS. For example, the brand mark brand association was the third highest rated association using the TBAS with the stadium and non-player personnel following closely behind. However, those associations were not salient in the minds of the participants when completing the open-ended question on the survey. In addition, while there is a social interaction construct in the TBAS this construct measures time spent with friends and meeting other people. The theme of bonding or interacting with family which was uncovered by Leximancer is not accounted for in the TBAS items.

In order to address RQ3 the participants were first segmented into low $(n=8)$, moderate $(n=117)$, and high $(n=260)$ levels of identification. MANOVA was then conducted to determine if any significant differences existed in the brand association constructs of the TBAS at the various levels of identification. The MANOVA determined that there were significant differences in the TBAS constructs at the various levels of identification $(\Lambda=.524, F(2,372)=12.894, p<.001)$. Post hoc tests revealed that those with high levels of identification had significantly higher ratings for all the TBAS constructs when compared to those with moderate and low levels of identification, with one exception. The team history construct was significantly higher for those with high levels of identification when compared to those with moderate levels of identification; however, no significant differences existed in this construct between participants with high and low levels of identification. In addition, those with moderate levels of identification had significantly higher ratings of the TBAS constructs of concessions, social interaction, team play characteristics, and non-player personnel when compared to those with low levels of identification. All other comparisons between moderately identified and low identified participants were not significant. Given the significant differences that were uncovered by the MANOVA it was determined that examining the difference in the brand concept maps at various levels of identification was warranted. However, given the small number of participants with low levels of identification $(n=8)$, comparisons were only made between the Leximancer results of those with moderate ( $n=117, M=5.13)$ and high levels of identification $(n=260, M=6.68)$. 
Figure 2 Leximancer brand concept map for highly identified fans only (see online version for colours)

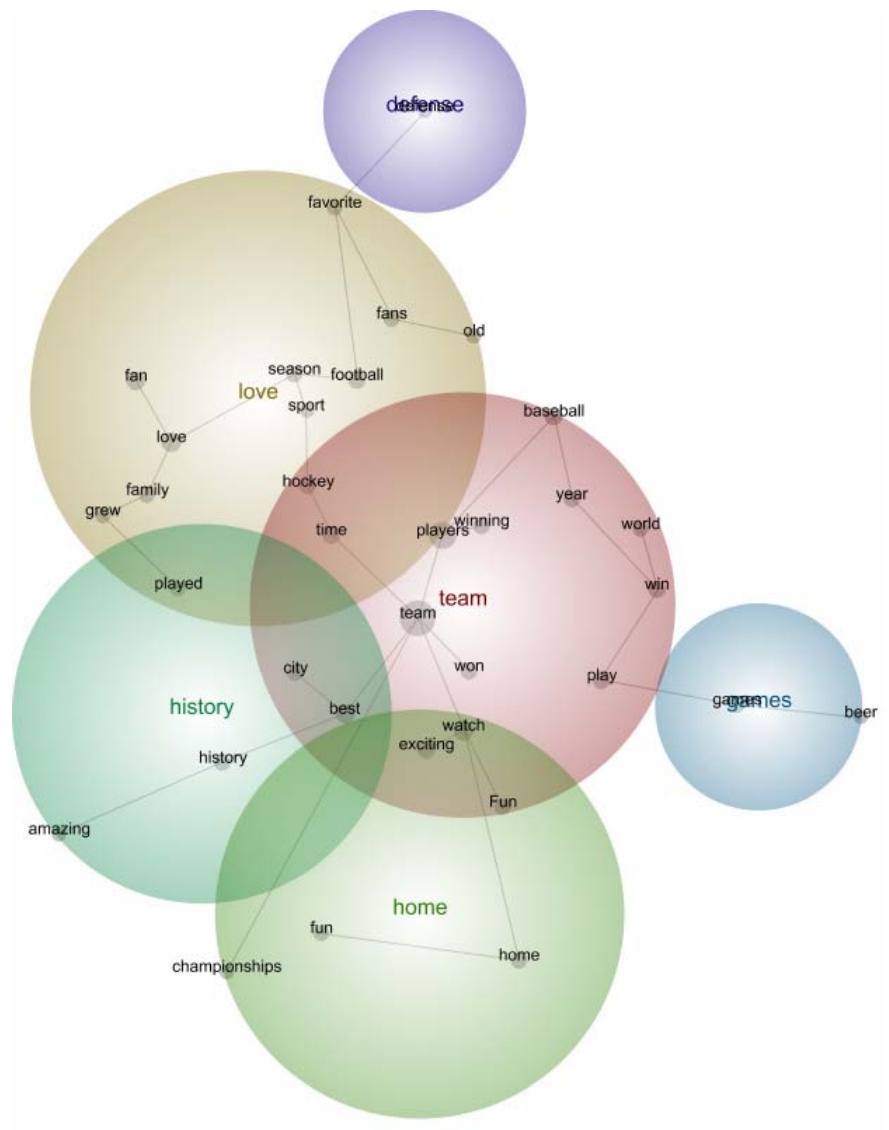

When examining the brand concept map for the highly identified participants (see Figure 2) a number themes emerged with a good deal of overlap: team $(n=157)$, love $(n$ $=81)$, home $(n=40)$, history $(n=29)$, games $(n=17)$, and defence $(n=4)$. The team theme included a variety of descriptors which represented associations such mentions of the players $(n=45)$, team success (represented by win, $n=16$, winning, $n=11$, and won, $n=11$ ), and the enjoyment of watching the team play (represented by watch, $n=11$ and exciting, $n=13$ ). The other brand association themes of love, history, and home had significant overlap with the team theme, and some overlap with each other as well. Further analysis of these themes uncovered that the love theme included the fan's expressing their fandom (i.e., identification with the team) and indicating that they have been a fan of the team for a long period of time (represented by fan, $n=22$, favourite, $n=$ 10 , and time, $n=15)$. The theme of home represented more an appreciation for the team representing the fan's home $(n=15)$ or hometown, highlighting a sense of internalisation 
or a feeling of connectedness with the team. The last of the interconnected themes was history which held associations of a long history or history of success (represented by history, $n=12$ and best, $n=22$ ). The peripheral/secondary themes of games and defense did not overlap with the other brand associations but represented the experiential component of going to or watching the games and a style of play association respectively.

Figure 3 Leximancer brand concept map for moderately identified fans only (see online version for colours)

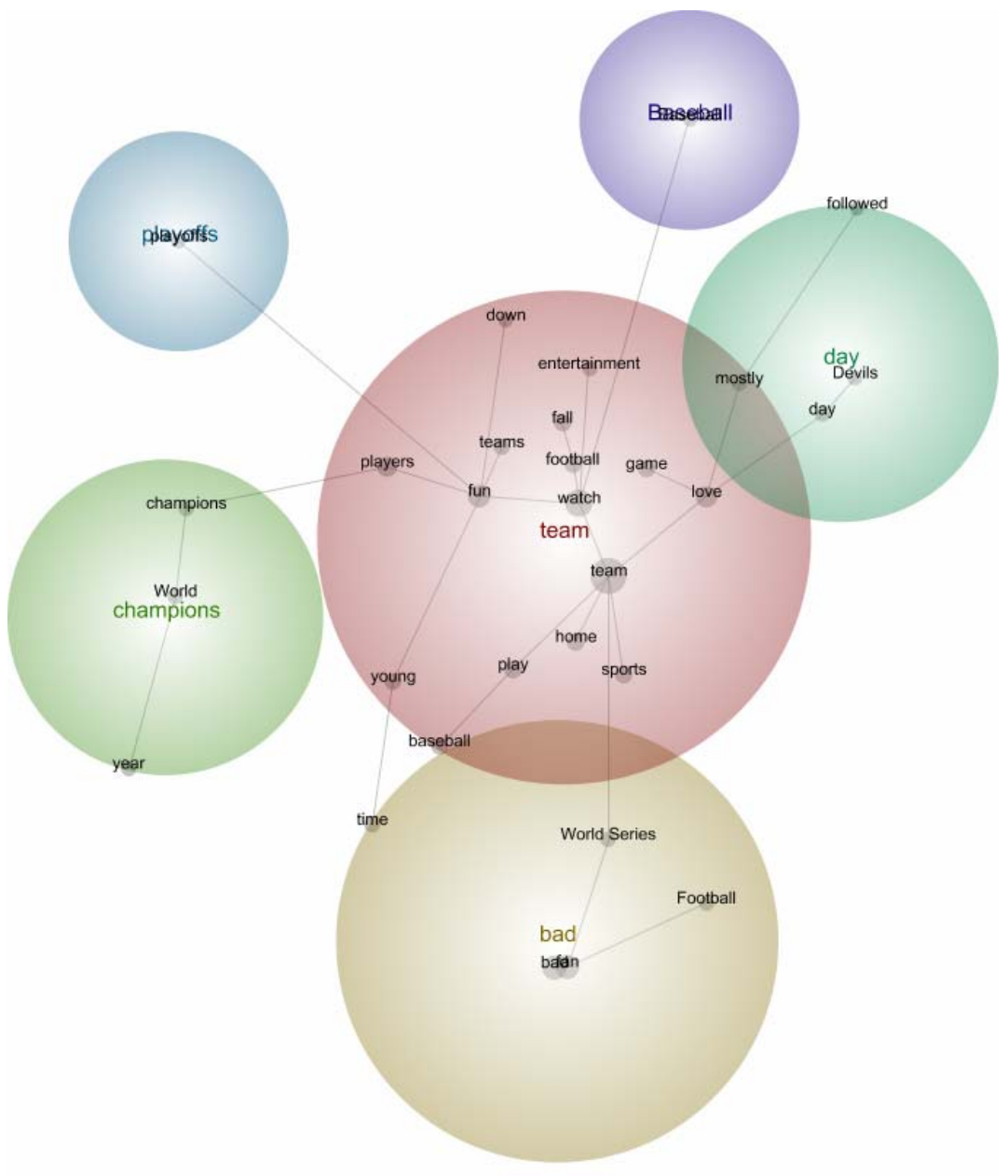

When examining the brand concept map for the participants with moderate levels of identification, several primary themes emerged once again (see Figure 3). Those themes included team $(n=62)$, bad $(n=23)$, champions $(n=9)$, day $(n=6)$, playoffs $(n=4)$, and baseball $(n=2)$. When examining the main theme of team some similarities to the concept map for highly identified fans in Figure 2 emerged. For example, this theme of team also included associations related to the team's players $(n=9)$, the enjoyment of watching the team and play (represented by watch, $n=17$, fun, $n=11$, and entertainment, $n=2$ ). The team theme for moderately identified fans also included the expression of 
one's fandom (represented by love, $n=8$ ) and a connection to the team as the hometown team (represented by home, $n=4$ ). While these associations of fandom and hometown team were present for moderately identified fans, they were not as strong as an association for those that were highly identified. For highly identified fans both brand associations were strong enough to be their own themes, while they were connected as descriptors or associations under the team theme for moderately identified fans.

Also, in comparison to the brand concept map for the highly identified participants in Figure 2, there is a lack of overlap or interconnectedness in the associations for fans with moderate levels of identification. This lack of overlap suggests that those with lower levels of identification have not developed as strong of a brand association network in memory as highly identified fans. In addition, this was the first instance that any negative brand associations were uncovered as a common theme in any of the analyses conducted in this study. Specifically, the negative associations of poor performance (represented by $\mathrm{bad}, n=23$ ) or the sense that 'one day' the team will be successful (represented by day, $n=6$ ) were highlighted for fans with moderate levels of identification, but not for fans with high levels of identification.

\section{Discussion}

In examining the salient brand associations uncovered by Leximancer in RQ1, a number of different types of brand associations were present. Specifically, there was a strong focus on product attribute related associations of the team's players, team history, team success, and the team's style of play. In addition, the team's style of play was often described using terms which would be considered to be elements of brand personality, which is when human characteristics are utilised to describe a brand (Aaker, 1997). For example, words such exciting, fun, amazing, entertaining, talented, tough, and hardworking were prevalent in the participant's responses, and some can be found as descriptors in the brand concept maps for the full sample and for both the highly and moderately identified fans (see Figures 1, 2 and 3). One benefit related association of social interaction with family and an attitude association of psychological connection to the team were also present. The focus on product related attributes was not surprising as these types of brand associations are commonly used as positioning strategies (Aaker, 1991). As such, there is an increased likelihood of exposure to these types of brand associations in team marketing activities. In addition, as the participants' brand associations for their favourite teams were being measured it is likely that they would have had multiple interactions with the team's brand over time in order to develop these specific product attribute related associations. However, the benefit of using Leximancer to uncover these brand associations is the results reveal which specific associations are most prevalent in a fan's memory and have strong connections to the brand. From a practical perspective this is important to understand as brand associations have a strong connection to purchase intent and team loyalty (Aaker, 1996; Ross, 2006). As such, measuring team brand associations using the method in this study provides teams with a true understanding of what associations are most important to their fan base so they can then tailor their marketing efforts around these associations. However, to get a full understanding of Leximancer's ability to be used to measure team brand associations it was important to compare the results with a scaled measurement. 
RQ2 provided a comparison between the results uncovered in RQ1 and the measurement of team brand associations using the TBAS. As previously mentioned, there were some similarities and differences in the results. The TBAS constructs of commitment, team history, team success, and team play characteristics were primary brand association themes also uncovered by the Leximancer analysis of the brand association free-thought listing question. However, the differences between the TBAS ratings and the Leximancer results in RQ1 highlight the benefits of using Leximancer to measure team brand associations. As mentioned, the brand mark association was the third highest rated construct in the TBAS, while it was not uncovered as a common brand association theme by Leximancer. This is likely due to the stark differences in the measurement techniques. The TBAS gives participants items which they then either agree or disagree with. For example, for the brand mark construct the participants would agree or disagree with the following: the team has distinctive colours, the symbol of the team is unique, and the team's logo is different from others. An individual may agree with these statements when primed with these items in a scaled response, but that does not necessarily measure if it is a salient brand association with the team. However, analysing the responses to the unaided free-thought listing question through Leximancer does provide an analysis of the most commonly mentioned brand associations, thus highlighting which brand associations are most commonly held in the fans' memory.

In addition, the Leximancer analysis allows for the potential to uncover brand associations which are potentially not captured by a pre-existing scale. For instance, the social interaction TBAS construct was the second lowest rated of the 11 TBAS associations. However, the association with family and bonding or interacting with family members was a common response uncovered by Leximancer. This may have occurred due to the semantics of scaled items. The social interaction TBAS construct includes the items of: the team offers me a place to spend time with friends, being a fan of the team is a good way to meet other people, I am able to see friends because of the team, and the team provides a good place to see friends. In the TBAS there are no items which measure the social interaction of spending time with family and each fan's definition of what constitutes 'seeing friends', 'spending time with friends', or 'meeting other people' may be different. For instance, one person may think that 'meeting other people' would simply mean to attend games with friends, while another person may take that same item to mean meeting new people at sporting events. Analysing the brand association free-thought listing question with Leximancer removes this ambiguity and allows to capture the specific thoughts of fans.

On top of uncovering the most salient associations, or uncovering new or unique brand associations, a benefit of using Leximancer is its ability to capture and visualise team brand association networks. For example, branching off of the team theme in Figure 1 is the following connection of words: players - won - exciting - winning championships. This indicates that these concepts were interconnected in the text and thus formed an interconnected brand association network. That is, a participant's first thought when they think of their favourite team may be the players, which then activates a further node in their memory about a particular victory or aspect of team success, which further activates the node in memory of the product benefit association of the excitement of that particular time and/or player. Leximancer allows for this visualisation of brand association networks and the first and second order associations which cannot be captured by a scaled measurement. This automated analysis conducted by Leximancer removes any bias from previous methods of developing brand concept maps by hand 
(John et al., 2006). From a practical perspective, teams could examine a result such as this and determine that they may want to create an advertisement showcasing an exciting moment in the team's history which focuses on certain players. Doing so will not only highlight which associations are most important for the fans but will also strengthen this association in the fan's memory due to the repeated exposure. As such, these associations will be more likely to be stored in memory and able to be retrieved at a later date (Wickelgren, 1981).

The analysis of RQ3, and the comparison of the Leximancer output for highly identified and moderately identified fans, also provides some evidence of the benefits of using this method to measure team brand associations. As mentioned, some of the same brand associations were uncovered for the highly identified and moderately identified fans. However, the differences between the two once again illustrate the benefit of using this type of analysis. First, when examining both of the brand concept maps in Figures 2 and 3 there is a significant amount of overlap in themes for highly identified fans, whereas there is limited overlap for moderately identified fans. This indicates that highly identified fans have a much more robust and developed brand association network, thus supporting previous research which indicates that highly identified fans generally have higher ratings of team brand associations (e.g., Ross and James, 2007; Walsh and Ross, 2010). That is, highly identified fans will access more team brand associations from memory which are strongly connected to one another in memory, whereas fans with moderate levels of identification may have similar team brand associations but they are not as strong or accessible from their memory. This would then also lead to individuals with higher levels of identification having different associations than those with lower levels of identification (Schnittka et al., 2012). In addition, in all of the analyses conducted, negative associations of poor team performance only appeared in the brand concept maps for the moderately identified fans. While these themes were uncovered by Leximancer it can be difficult to analyse negative associations using preexisting scales. For example, in this study the team success TBAS construct was rated somewhat high by those with moderate levels of identification $(M=5.18)$; however, there were enough moderately identified fans who mentioned the team's poor performance in response to the free-thought listing question for this to be uncovered by Leximancer as a brand association theme. This again highlights the ability of the method employed in this study to capture unique and relevant team brand associations which may not be captured using a preexisting scale. In this case, it is just as important for teams to know what their negative brand associations are as it is to understand any positive team brand associations so they can address, and attempt to change, any negative team brand associations.

\section{Limitations and future research}

This study adds considerably to the research on team brand associations by introducing a new method of team brand association measurement which accurately measures salient team brand associations and visually depicts brand association networks. However, it is not without its limitations. First, this study did not focus on one specific team but rather captured the brand associations fans have for their favourite professional sports team. While this allowed for the measurement of team brand associations as a whole, it may not capture unique associations certain teams may have. As such, future research should test 
this method with one individual team to examine the utility of using Leximancer on a team-by-team basis, while also focusing on expanding the sample size to help improve generalisability.

Future research should also focus on capturing samples with a broader base of identification with teams. In general, the participants in this study had high levels of team identification. As such, it was not possible to use Leximancer to analyse team brand associations from participants with low levels of identification. Future research should capture participants at all levels of identification in order to fully examine the development of team brand association networks. As there were differences in the team brand association networks in this study between those with high and moderate levels of identification, it is anticipated that there would be additional differences with participants who have lower levels of identification with the team.

Further, this study could be replicated to measure sport league brand associations which is an emerging area of brand association research in sport (see Kunkel et al., 2014). In addition, it would be beneficial to measure team brand associations at different time periods. As demonstrated by Kunkel et al. (2016) team brand associations will change for fans over time as they continue to experience and interact with the team and the team's marketing activities. Leximancer may provide a good outlet to visually depict and measure these any potential longitudinal brand association change throughout a season or after exposure to marketing activities.

\section{Acknowledgements}

This work was supported, in part, by funds provided by the David B. Falk College of Sport and Human Dynamics, Syracuse University.

\section{References}

Aaker, D.A. (1991) Managing Brand Equity, The Free Press, New York.

Aaker, D.A. (1996) Building Strong Brands, The Free Press, New York.

Aaker, J.L. (1997) 'Dimensions of brand personality', Journal of Marketing Research, Vol. 34, No. 3, pp.347-356.

Abeza, G., Pegoraro, A., Naraine, M.L., Sequin, B. and O'Reilly, N. (2014) 'Activating a global sport sponsorship with social media: An analysis of TOP sponsors, Twitter, and the 2014 Olympic games', International Journal of Sport Management and Marketing, Vol. 15, Nos. 3-4, pp.184-212.

Biscaia, R., Correia, A., Ross, S., Rosado, A. and Maroco, J. (2013) 'Spectator-based brand equity in professional soccer', Sport Marketing Quarterly, Vol. 22, No. 1, pp.20-32.

Cacioppo, J.T. and Petty, R.E. (1981) Social psychological procedures for cognitive response assessment: the thought-listing technique', in Merluzzi, T.V. et al (Eds.): Cognitive Assessment, pp.309-342, Guilford Press, New York.

Campbell, C., Pitt, L.E., Parent, M. and Berthon, P.R. (2011) 'Understanding consumer conversations around ads in a web 2.0 world', Journal of Advertising, Vol. 40, No. 1, pp.87-102.

Chen, C.H. (2001) 'Using free association to examine the relationship between characteristics of brand associations and brand equity', Journal of Product and Brand Management, Vol. 10, Nos. 6-7, pp.439-451. 
Frederick, E.L., Stocz, M. and Pegoraro, A. (2016) 'Players, punishment, and perception: an analysis of the response to the Tony Stewart - Kevin Ward Jr. incident on Facebook', Sport in Society, Vol. 19, No. 10, pp.1460-1477.

Gladden, J.M. and Funk, D.C. (2002) 'Developing an understanding of brand associations in team sport: Empirical evidence from consumers of professional sport', Journal of Sport Management, Vol. 16, No. 1, pp.54-81.

Gladden, J.M. and Milne, G.R. (1999) 'Examining the importance of brand equity in professional sports', Sport Marketing Quarterly, Vol. 8, No. 1, pp.21-29.

Gladden, J.M., Irwin, R. and Sutton, W.A. (2001) 'Managing North American professional sport teams in the new millennium: a focus on building brand equity', Journal of Sport Management, Vol. 15, No. 4, pp.297-317.

Gladden, J.M., Milne, G.R. and Sutton, W.A. (1998) 'A conceptual framework for evaluating brand equity in Division I college athletics', Journal of Sport Management, Vol. 12, No. 1, pp.1-19.

Grace, D. and O'Cass, A. (2002) 'Brand associations: looking through the eye of the beholder', Qualitative Market Research: An International Journal, Vol. 5, No. 2, pp.96-111.

Hair, J., Black, W., Babin, B. and Anderson, R. (2010) Multivariate Data Analysis, 7th ed., Prentice Hall, New Jersey.

Heere, B. (2010) 'A new approach to measure perceived brand personality associations among consumers', Sport Marketing Quarterly, Vol. 19, No. 1, pp.17-24.

Hu, L. and Bentler, P.M. (1999) 'Cutoff criteria for fit indicies in covariance structure analysis: conventional criteria versus new alternatives', Structural Equation Modeling, Vol. 6, No. 1, pp.1-55.

John, D.R., Loken, B., Kim, K. and Monga, A.B. (2006) 'Brand concept maps: a methodology for identifying brand associations networks', Journal of Marketing Research, Vol. 43, No. 4, pp.549-563.

Keller, K. (1993) 'Conceptualizing, measuring, and managing customer-based brand equity', Journal of Marketing, Vol. 57, No. 1, pp.1-22.

Kowalczyk, C.M. and Royne, M.B. (2013) 'The moderating role of celebrity worship on attitudes toward celebrity brand extensions', Journal of Marketing Theory and Practice, Vol. 21, No. 2, pp.211-220.

Kunkel, T., Doyle, J.P., Funk, D.C., Du, J., and McDonald, H. (2016) 'The development and change of brand associations and their influence on team loyalty over time', Journal of Sport Management, Vol. 30, No. 2, pp.117-134.

Kunkel, T., Funk, D. and King, C. (2014) 'Developing a conceptual understanding of consumer-based league brand associations', Journal of Sport Management, Vol. 28, No. 1, pp.49-67.

Naraine, M.L. and Parent, M.M. (2016) 'Birds of a feather: 'an institutional approach to Canadian national sport organizations' social-media use', Journal of Sport Management, Vol. 9, No. 2, pp.140-162.

Nunnally, J.C. and Bernstein, I.H. (1994) Psychometric Theory, 3rd ed., McGraw Hill, New York.

Pegoraro, A., Burch, L.M., Frederick, E. and Vincent, C. (2014) 'I am not loving it: examining the hijacking of \#CheersToSochi', International Journal of Sport Management and Marketing, Vol. 15, Nos. 3-4, pp.163-183.

Ross, S.D. (2006) 'A conceptual framework for understanding spectator-based brand equity', Journal of Sport Management, Vol. 20, No. 1, pp.22-38.

Ross, S.D. and James, J. (2007) 'The influence of psychological connection on professional sport team brand associations', International Journal of Sport Management, Vol. 8, No. 1, pp.115-129.

Ross, S.D., Bang, H. and Lee, S. (2007) 'Assessing brand associations for intercollegiate ice hockey', Sport Marketing Quarterly, Vol. 16, No. 2, pp.106-114. 
Ross, S.D., James, J. and Vargas, P. (2006) 'Development of a scale to measure team brand associations in professional sport', Journal of Sport Management, Vol. 20, No. 2, pp.260-279.

Ross, S.D., Russell, K.C. and Bang, H. (2008) 'An empirical assessment of spectator-based brand equity', Journal of Sport Management, Vol. 22, No. 3, pp.322-337.

Schnittka, O., Sattler, H. and Zenker, S. (2012) 'Advanced brand concept maps: a new approach for evaluating the favorability of brand association networks', International Journal of Research in Marketing, Vol. 29, No. 3, pp.265-274.

Sotiriadou, P., Brouwers, J. and Le, T.A. (2014) 'Choosing a qualitative data analysis tool: a comparison of NVivo and Leximancer', Annals of Leisure Research, Vol. 17, No. 2, pp.218-234.

Supphellen, M. (2000) 'Understanding core brand equity: guidelines for in-depth elicitation of brand associations', International Journal of Market Research, Vol. 42, No. 3, pp.319-338.

Walsh, P. and Ross, S.D. (2010) 'Examining brand extensions and their potential to dilute team brand associations', Sport Marketing Quarterly, Vol. 19, No. 4, pp.196-206.

Walsh, P. and Williams, A. (2017) 'To extend or not extend a human brand: an analysis of perceived fit and attitudes towards athlete brand extensions', Journal of Sport Management, Vol. 31, No. 1, pp.44-60.

Walsh, P., Chien, C.J. and Ross, S.D. (2012) 'Sport teams as brand extensions: a case of Taiwanese baseball', Sport Marketing Quarterly, Vol. 21 No. 3, pp.138-146.

Walsh, P., Clavio, G., Lovell, M.D. and Blaszka, M. (2013) 'Differences in event brand personality between social media users and non-users', Sport Marketing Quarterly, Vol. 22, No. 4, pp.214-223.

Walsh, P., Williams, A., Kim, D.Y. and Choi, W. (2015) 'What a team brand means to youth: an examination of team brand associations held by youth fans', International Journal of Sport Management, Recreation, and Tourism, Vol. 19, No. C, pp.40-61.

Wickelgren, W.A. (1981) 'Human learning and memory', Annual Review of Psychology, Vol. 32, pp.21-52.

Williams, A., Kim, D.Y., Choi, W. and Walsh, P. (2015) 'What children love about athletes: an exploratory assessment of athlete brand associations among youth consumers', Global Sport Business Journal, Vol. 3, No. 1, pp.63-77. 